\title{
ANALYSIS OF THE INFLUENCE OF JOB STRESS AND JOB SATISFACTION ON TURNOVER INTENTION AT SALES EMPLOYEE PT SINAR MUTIARA CAKRABUANA JAKARTA
}

\author{
Widya Kurniawati, Putut Haribowo², Khairul Saleh \\ Administrasi Bisnis, Politeknik Negeri Semarang, Semarang, Indonesia \\ email: ${ }^{2}$ putut haribowo@polines.ac.id
}

\begin{abstract}
This study aims to find out (1) the influence of job stress on turnover intention at PT Sinar Mutiara Cakrabuana, (2) The influence of job satisfaction on turnover intention at PT Sinar Mutiara Cakrabuana, and (3) The influence of job stress and job satisfaction on turnover intention at PT Sinar Mutiara Cakrabuana. The collecting data methods used in this study were interview, questionnaires, and literature studies. The scale of questionnaires used agreedisagree scale with 10 point scale. The sample in this study were 60 Sales employees of PT Sinar Mutiara Cakrabuana. The data analysis technique used was multiple linear regression. The results of multiple linear regression showed that job stress had a positive and significant influence on turnover intention, and job satisfaction had a negative and significant influence on turnover intention. Job stress and job satisfaction given contribute $30.4 \%$ to turnover intention. That means that 30.4\% turnover intention was explained by job stress and job satisfaction, while $69.6 \%$ was explained by other factors not examined in this study.
\end{abstract}

Keywords: job stress, job satisfaction, and turnover intention

\section{ANALISIS PENGARUH STRES KERJA DAN KEPUASAN KERJA TERHADAP KEINGINAN BERPINDAH PADA KARYAWAN SALES PT SINAR MUTIARA CAKRABUANA JAKARTA}

\begin{abstract}
ABSTRAK
Penelitian ini bertujuan untuk mengetahui (1) Pengaruh stres kerja terhadap keinginan berpindah pada PT Sinar Mutiara Cakrabuana, (2) Pengaruh kepuasan kerja terhadap keinginan berpindah pada PT Sinar Mutiara Cakrabuana, dan (3) Pengaruh stres kerja dan kepuasan kerja terhadap keinginan berpindah pada PT Sinar Mutiara Cakrabuana. Metode pengumpulan data yang digunakan dalam penelitian ini adalah wawancara, kuesioner, dan studi pustaka. Skala kuesioner menggunakan agree-disagree scale dengan skala 10 poin. Sampel pada penelitian ini adalah 60 karyawan Sales PT Sinar Mutiara Cakrabuana. Teknik analisis data yang digunakan adalah regresi linear berganda. Hasil regresi linear berganda menunjukan bahwa stres kerja bepengaruh positif dan signifikan terhadap keinginan berpindah, serta kepuasan kerja berpengaruh negatif dan signifikan terhadap keinginan berpindah. Stres kerja dan kepuasan kerja memberikan kontribusi sebesar 30,4\% pada keinginan berpindah. Itu berarti bahwa 30,4\% keinginan berpindah dijelaskan oleh stres kerja dan kepuasan kerja, sedangkan 69,6\% dijelaskan oleh faktor lain yang tidak diteliti dalam penelitian ini.
\end{abstract}

Kata kunci: stres kerja, kepuasan kerja, keinginan berpindah 


\section{PENDAHULUAN}

Era Globalisasi semakin berkembang pesat di dunia. Perkembangan tersebut juga didukung oleh pemberlakuan MEA (Masyarakat Ekonomi ASEAN) yang menyebabkan lalu lintas perdagangan bebas di kawasan Asia Tenggara menjadi tanpa kendali. MEA tidak hanya membuka arus perdagangan barang atau jasa, tetapi juga tenaga kerja profesional. Oleh karena itu, MEA akan mempengaruhi secara langsung tenaga ahli di Indonesia. Perusahaan di Indonesia diharapkan memiliki sumber daya manusia yang baik, sehingga perusahaan-perusahaan tersebut siap dan mampu bersaing dalam lingkup MEA.

Berdasarkan laporan yang dilakukan oleh Hay Group pada tahun 2013 tingkat turnover karyawan di Indonesia mencapai $25,8 \%$ dan menjadi negara dengan tingkat turnover karyawan tertinggi nomer tiga di dunia. Menurut Yan, Zhu dan Hall dalam Bhatnaghar (2014:1401) "Keinginan berpindah telah muncul sebagai senyawa terkuat dari turnover". Dalam hal ini, seseorang memiliki keinginan untuk meninggalkan perusahaan dapat disebabkan oleh beberapa faktor. Menurut Purani dan Sadewa dalam Ramamurthi et al. (2016:529) mengatakan "Keinginan berpindah dapat didefinisikan sebagai rencana karyawan untuk meninggalkan atau berhenti dari pekerjaan mereka saat ini atau perusahaan dan bergerak maju dengan melihat lain tawaran yang lebih baik".

Hal ini didukung oleh Robbins dalam Sunaryo dan Pantius (2014:6) mengatakan "Munculnya keinginan untuk pindah atau keluar dari pekerjaan (turnover intention) dapat diakibatkan oleh timbulnya stres kerja". Di sisi lain Alnacik, Erat, dan Akcin dalam Octaviani (2015:116) menegaskan bahwa "Kepuasan kerja merupakan senyawa penting apakah seorang karyawan memiliki keinginan untuk bertahan atau meninggalkan organisasi tempat ia bekerja".

Salah satu perusahaan yang mengalami tingkat turnover setiap tahunnya adalah PT Sinar Mutiara Cakrabuana. PT Sinar Mutiara
Cakrabuana merupakan perusahaan yang menyediakan peralatan pneumatik dengan merek SMC mulai tahun 1984. Untuk PT Sinar Mutiara Cakrabuana hasil dari wawancara para karyawan Sales PT Sinar Mutiara Cakrabuana, hasilnya setiap tahun selalu mengalami naik turun turnover karyawan seperti pada Tabel 1.

Tabel 1 Jumlah Karyawan Sales PT Sinar Mutiara Cakrabuana

\begin{tabular}{|c|c|c|}
\hline Tahun & $\begin{array}{c}\text { Total } \\
\text { Karyawan } \\
\text { Sales }\end{array}$ & $\begin{array}{c}\text { Karyawan } \\
\text { Sales Yang } \\
\text { Keluar }\end{array}$ \\
\hline 2014 & 45 orang & 5 orang \\
\hline 2015 & 55 orang & 10 orang \\
\hline 2016 & 55 orang & 8 orang \\
\hline 2017 & 60 orang & 13 orang \\
\hline
\end{tabular}

Sumber: Laporan PT Sinar Mutiara

Cakrabuana (2018)

PT Sinar Mutiara Cakrabuana pada tahun 2014 mengalami turnover sebesar 11,11\%, kemudian tahun 2015 meningkat menjadi $18,18 \%$, tahun 2016 mulai turun lagi menjadi 14,54\%, dan terakhir tahun 2017 meningkat pesat menjadi $21,67 \%$. Hal itu menyimpulkan bahwa terjadi turnover setiap tahunnya di PT Sinar Mutiara Cakrabuana karena beberapa karyawan keluar atau pindah pekerjaan.

Berdasarkan uraian tersebut penulis ingin melakukan penelitian dengan judul "Analisis Pengaruh Stres Kerja Dan Kepuasan Kerja Terhadap Keinginan Berpindah Pada Karyawan Sales PT Sinar Mutiara Cakrabuana Jakarta".

\section{Tujuan Penelitian}

Penelitian ini dilakukan dengan tujuan sebagai berikut:

1. Menganalisis pengaruh stres kerja terhadap keinginan berpindah pada karyawan Sales PT Sinar Mutiara Cakrabuana.

2. Menganalisis pengaruh kepuasan kerja terhadap keinginan berpindah pada 
karyawan Sales PT Sinar Mutiara Cakrabuana.

3. Menganalisis pengaruh stres kerja dan kepuasan kerja terhadap keinginan berpindah pada karyawan Sales PT Sinar Mutiara Cakrabuana.

\section{Manfaat Penelitian}

Penelitian ini diharapkan dapat memberikan manfaat sebagai berikut:

1. Bagi Penulis

Dapat menambah wawasan dan pengetahuan tentang faktor-faktor yang menyebabkan stres kerja dan kepuasan kerja di suatu perusahaan. Wawasan dan pengetahuan tersebut nantinya dapat dijadikan bekal dalam menghadapi dunia kerja, serta memberikan pemahaman antara teori-teori yang dipelajari dengan penerapannya dalam dunia kerja.

2. Bagi PT Sinar Mutiara Cakrabuana

Sebagai tambahan referensi dan masukan yang dapat menjadi bahan pertimbangan dan evaluasi bagi pihak perusahaan dalam menekan tingkat keinginan berpindah di perusahaan tersebut.

3. Bagi Politeknik Negeri Semarang Penelitian ini diharapkan dapat menjadi salah satu sumber referensi bacaan dan tambahan informasi mengenai keinginan berpindah bagi mahasiswa yang akan menyusun laporan Tugas Akhir/Skripsi.

\section{Tinjauan Pustaka}

\section{Keinginan Berpindah}

Ma dan Trigo dalam Wong et al. (2014:72) mengatakan "Keinginan berpindah adalah sejauh mana karyawan berniat untuk berhenti dari pemimpin organisasi mereka".

Mobley dalam Pawesti dan Rinandita (2016:53) juga menggariskan secara detail faktor internal yang mempengaruhi terjadinya turnover yaitu:

1. Budaya Organisasi. Kepuasan terhadap kondisi-kondisi kerja dan kepuasan terhadap kerabat-kerabat kerja merupakan faktor-faktor yang dapat menentukan turnover.
2. Gaya Kepemimpinan. Kepuasan terhadap pemimpin dan variabel-variabel lainnya seperti sentralisasi merupakan faktor-faktor yang menentukan turnover.

3. Kompensasi. Penggajian dan kepuasan terhadap pembayaran merupakan faktorfaktor yang dapat menentukan turnover.

4. Kepuasan Kerja. Kepuasan terhadap pekerjaan, secara menyeluruh dan kepuasan terhadap bobot pekerjaan merupakan faktor-faktor yang dapat menentukan turnover.

5. Karir. Kepuasan terhadap promosi merupakan salah satu faktor yang menentukan turnover.

\section{Stres Kerja}

Menurut Zainal et al. (2014) "Stres kerja adalah suatu kondisi ketegangan yang menciptakan adanya ketidakseimbangan fisik dan psikis, yang mempengaruhi emosi, proses berpikir, dan kondisi seorang karyawan".

Menurut Munandar (2014:381), faktor-faktor intrinsik yang dapat membangkitkan stres kerja yaitu:

a. Tuntutan fisik

b. Tuntutan tugas

c. Peran individu dalam organisasi

d. Pengembangan karir

e. Hubungan dalam pekerjaan

f. Struktur dan iklim organisasi

g. Tuntutan dari luar organisasi atau pekerjaan

\section{Kepuasan Kerja}

Menurut Priyono dan Marnis (2008:228-229) menyatakan "Kepuasan kerja juga dapat dinyatakan sebagai keadaan emosional karyawan di mana terjadi titik temu antara nilai balas jasa kerja dengan oleh perusahaan dengan tingkat balas jasa yang diinginkan karyawan".

Menurut Robbins dan Judge (2018:56) ada beberapa dampak dari ketidakpuasan kerja yang dihasilkan oleh karyawan, yaitu:

a. Keluar (exit): perilaku yang ditunjukkan untuk meninggalkan organisasi termasuk 
mencari posisi baru dan mengundurkan diri.

b. Aspirasi (voice): secara aktif dan kontsruktif berusaha memperbaiki kondisi, termasuk menyarankan perbaikan, mendiskusikan masalah dengan atasan, dan beberapa bentuk aktivitas serikat kerja.

c. Kesetiaan (loyalty): secara pasif tetapi optimis menunggu membaiknya kondisi, termasuk membela organisasi ketika berhadapan dengan kecaman eksternal dan mempercayai organisasi dan manajernya untuk melakukan hal yang benar.

d. Pengabaian (neglect): secara pasif membiarkan kondisi menjadi lebih buruk, termasuk ketidakhadiran atau keterlambatan yang terus-menerus kurangnya usaha, dan meningkatnya angka kesalahan.

\section{METODE}

Populasi pada penelitian ini adalah 60 karyawan Sales PT Sinar Mutiara Cakrabuana. Teknik sampling yang digunakan pada penelitian ini adalah teknik sampling jenuh, pada teknik pengambilan sampel ini semua anggota populasi dijadikan sampel yaitu 60 karyawan Sales. Skala pengukuran yang digunakan adalah skala interval, dan jenis skala interval yang digunakan dalam penelitian ini adalah agreedisagree scale.

Metode analisis data yang digunakan adalah:

1. Analisis Deskriptif

Analisis deskriptif digunakan untuk memberikan gambaran deskriptif empiris atas data yang dikumpulkan dalam penelitian.

2. Uji Validitas dan Uji Reliabilitas

Instrumen yang digunakan dalam penelitian ini berupa kuesioner, untuk itu terlebih dahulu instrumen diuji apakah instrumen yang digunakan dalam penelitian ini layak atau tidak. Uji instrumen yang dimaksud adalah uji validitas dan reliabilitas.
3. Uji Asumsi Klasik

Uji asumsi klasik yang digunakan dalam penelitian ini antara lain uji multikolinieritas, uji heteroskesdastisitas, dan uji normalitas.

4. Analisis Regresi Linear Berganda

Analisis ini bertujuan untuk meramalkan bagaimana keadaan (naik turunnya) variabel dependen, bila dua atau lebih variabel independen sebagai faktor prediktor dimanipulasi (Sugiyono, 2014:277).

5. Uji Hipotesis

a. Uji t

Uji statistik pada $\mathrm{t}$ pada dasarnya menunjukkan seberapa jauh pengaruh satu variabel penjelas/independen secara parsial dalam menerangkan variasi variabel dependen (Ghozali, 2016:97)

b. Uji F

Uji $F$ digunakan untuk mengetahui variabel independen secara bersamasama atau simultan mempengaruhi variabel dependen (Ghozali, 2016:171)

6. Analisis Koefisien Determinasi

Menurut Ghozali (2016:95) "Koefisien determinasi pada intinya mengukur seberapa jauh kemampuan model dalam menerangkan variasi variabel dependen".

\section{HASIL DAN PEMBAHASAN \\ Analisis Deskriptif}

Hasil analisis deskriptif dalam penelitian ini adalah sebagai berikut:

1. Variabel Stres Kerja

Jawaban responden mengenai stres kerja rata - rata sebesar 57,11\%, maka dapat dikatakan bahwa stres kerja pada karyawan Sales PT Sinar Mutiara Cakrabuana berada pada kategori sedang.

2. Variabel Kepuasan Kerja

Jawaban responden mengenai kepuasan kerja rata - rata sebesar 58,00\%, maka dapat dikatakan bahwa kepuasan kerja pada karyawan Sales PT Sinar Mutiara Cakrabuana berada pada kategori sedang. 
3. Variabel Keinginan Berpindah

Jawaban responden mengenai keinginan berpindah rata - rata sebesar 58,58\%, maka dapat dikatakan bahwa keingian berpindah pada karyawan Sales PT Sinar Mutiara Cakrabuana berada pada kategori sedang.

\section{Uji Validitas}

Adapun metode yang digunakan untuk menguji validitas dan reliabilitas pada penelitian ini adalah dengan menggunakan software SPSS 22. Hasil uji validitas variabel penelitian dapat dilihat pada Tabel 2.

Tabel 2 Uji Validitas Variabel

\begin{tabular}{|c|c|c|c|c|}
\hline $\begin{array}{c}\text { Varia- } \\
\text { Bel }\end{array}$ & $\begin{array}{c}\text { Perta- } \\
\text { nyaan }\end{array}$ & $\mathbf{r}_{\text {tabel }}$ & $\mathbf{r}_{\text {hitung }}$ & Ket \\
\hline \multirow{5}{*}{ (X1) } & X1.1 & 0,2542 & 0,587 & Valid \\
\cline { 2 - 5 } & X1.2 & 0,2542 & 0,711 & Valid \\
\cline { 2 - 5 } & X1.3 & 0,2542 & 0,644 & Valid \\
\cline { 2 - 5 } & X1.4 & 0,2542 & 0,73 & Valid \\
\cline { 2 - 5 } & X1.5 & 0,2542 & 0,828 & Valid \\
\cline { 2 - 5 } & X1.6 & 0,2542 & 0,845 & Valid \\
\cline { 2 - 5 } X1.7 & 0,2542 & 0,52 & Valid \\
\hline \multirow{5}{*}{} & X1.1 & 0,2542 & 0,742 & Valid \\
\cline { 2 - 5 } & X1.2 & 0,2542 & 0,668 & Valid \\
\cline { 2 - 5 } & X1.3 & 0,2542 & 0,702 & Valid \\
\cline { 2 - 5 } & X1.4 & 0,2542 & 0,823 & Valid \\
\cline { 2 - 5 } & X1.5 & 0,2542 & 0,913 & Valid \\
\cline { 2 - 5 } & X1.6 & 0,2542 & 0,871 & Valid \\
\cline { 2 - 5 } & X1.7 & 0,2542 & 0,812 & Valid \\
\cline { 2 - 5 } & X1.8 & 0,2542 & 0,799 & Valid \\
\hline \multirow{4}{*}{ (Y) } & Y.1 & 0,2542 & 0,893 & Valid \\
\cline { 2 - 5 } & Y.2 & 0,2542 & 0,864 & Valid \\
\cline { 2 - 5 } & Y.3 & 0,2542 & 0,796 & Valid \\
\cline { 2 - 5 } & Y.4 & 0,2542 & 0,824 & Valid \\
\hline
\end{tabular}

Sumber: Data primer yang diolah (2018)

\section{Uji Reliabilitas}

Adapun metode yang digunakan untuk menguji validitas dan reliabilitas pada penelitian ini adalah dengan menggunakan software SPSS 22. Hasil uji tingkat reliabilitas variabel dapat dilihat pada Tabel 3.

Tabel 3 Uji Reliabilitas Variabel

\begin{tabular}{|l|c|c|}
\hline Variabel & $\begin{array}{c}\text { Cronbach's } \\
\text { Alpha }\end{array}$ & Ket \\
\hline$(\mathrm{X} 1)$ & 0,824 & Reliabel \\
\hline$(\mathrm{X} 2)$ & 0,916 & Reliabel \\
\hline$(\mathrm{Y})$ & 0,864 & Reliabel \\
\hline
\end{tabular}

Sumber: Data primer yang diolah (2018)

\section{Uji Asumsi Klasik}

\section{Uji Multikolinieritas}

Pengujian multikolinearitas dilakukan dengan melihat nilai VIF (variance-inflating factor), dasar pengambilan keputusan jika VIF $\leq 10$ maka tidak terjadi korelasi di antara variabel bebas. Tabel 4 berikut ini merupakan hasil perhitungan menggunakan program SPSS 22:

Tabel 4 Hasil Uji Mulitikolinearitas

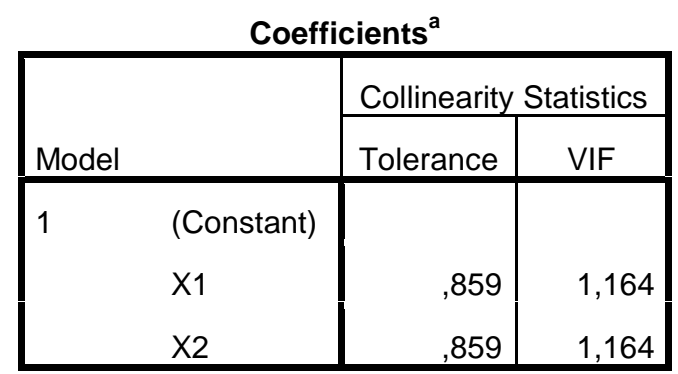

a. Dependent Variable: $Y$

Sumber: Data primer yang diolah (2018)

Berdasarkan Tabel 4 menunjukan bahwa nilai VIF 1,164 artinya nilai VIF $<10$. Dengan demikian, dapat disimpulkan bahwa tidak terjadi korelasi di antara variabel bebas.

\section{Uji Heteroskesdastisitas}

Uji Heteroskesdastisitas bertujuan menguji apakah dalam regresi terjadi ketidaksamaan varians dari residual suatu pengamatan ke pengamatan yang lain. Hasil dari uji heteroskesdastisitas menggunakan scatterplot dapat dilihat pada Gambar 1. 


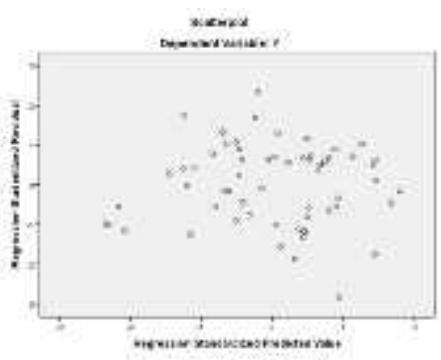

Sumber: Data primer yang diolah (2018)

Gambar 1 Hasil Uji Heteroskedastisitas

Berdasarkan Gambar 1 menunjukan titik-titik menyebar secara acak, di atas dan di bawah angka 0 pada sumbu Y. Dengan demikian, dapat disimpulkan bahwa tidak terjadi heteroskesdastisitas dalam model regresi ini.

\section{Uji Normalitas}

Pengujian normalitas dilakukan dengan menggungakan uji statistik KolmogorovSminov Test. Residual berdistribusi normal jika memiliki nilai signifikan > 0.05 , untuk residual regresi menggunakan software SPSS 22. Output yang dihasilkan disajikan pada Tabel 5.

Tabel 5 Hasil Uji Normalitas One-Sample Kolmogorov-Smirnov Test

\begin{tabular}{|ll|r|}
\hline & & \multicolumn{2}{|c|}{$\begin{array}{l}\text { Unstandardized } \\
\text { Predicted Value }\end{array}$} \\
\hline $\mathrm{N}$ & 60 \\
\hline Normal & Mean & 23,6000000 \\
Parameters $^{\mathrm{a}, \mathrm{b}}$ & Std. & 5,31381980 \\
& Deviation &, 099 \\
Most Extreme & Absolute &, 048 \\
Differences & Positive &,- 099 \\
& Negative &, 099 \\
Test Statistic & &, $200^{\mathrm{c}, \mathrm{d}}$ \\
\hline
\end{tabular}

a. Test distribution is Normal.

b. Calculated from data.

c. Lilliefors Significance Correction.

d. This is a lower bound of the true significance.

Sumber: Data primer yang diolah (2018)
Berdasarkan Tabel 5 diperoleh nilai sig 0,200 $\geq 0,05$, maka data tersebut berdistribusi normal.

\section{Analisis Regresi Linear Berganda}

Analisis ini digunakan untuk mengetahui variabel-variabel bebas (independen) yaitu stres kerja $\left(\mathrm{X}_{1}\right)$ dan kepuasan kerja $\left(\mathrm{X}_{2}\right)$, terhadap variabel terikat (dependen) yaitu keinginan berpindah (Y). Berdasarkan hasil pengujian regresi berganda dengan program SPSS 22, diperoleh hasil sebagai berikut:

Tabel 6 Hasil Analisis Regresi

\begin{tabular}{|c|c|c|c|c|}
\hline \multicolumn{5}{|c|}{ Coefficients $^{\mathrm{a}}$} \\
\hline \multirow[b]{2}{*}{ Model } & & \multicolumn{2}{|c|}{$\begin{array}{l}\text { Unstandardized } \\
\text { Coefficients }\end{array}$} & $\begin{array}{l}\text { Standardized } \\
\text { Coefficients }\end{array}$ \\
\hline & & B & $\begin{array}{c}\text { Std. } \\
\text { Error }\end{array}$ & \\
\hline 1 & $\begin{array}{l}\text { (Cons } \\
\text { tant) }\end{array}$ & 4,895 & 1,369 & \\
\hline & $\mathrm{X} 1$ & ,505 & , 144 & ,410 \\
\hline & $\mathrm{x} 2$ &,- 324 & ,139 &,- 274 \\
\hline
\end{tabular}

a. Dependent Variable: $Y$

Sumber: Data primer yang diolah (2018)

Berdasarkan Tabel 6 dapat diketahui bahwa seluruh variabel bebas yaitu stres kerja dan kepuasan kerja memiliki nilai sig. $<0.05$, hal ini berarti variabel bebas berpengaruh terhadap variabel terikat. Adapun model regresi linier berganda yang terbentuk adalah sebagai berikut:

$Y=4,895+0,505 X_{1}-0,324 X_{2}$

$\mathrm{Y}=$ Keinginan Berpindah

$\mathrm{X}_{1}=$ Stres Kerja

$\mathrm{X}_{2}=$ Kepuasan Kerja

Keterangan:

1. Konstanta $(\alpha=4,895)$

Artinya jika variabel stres kerja $\left(\mathrm{X}_{1}\right)$ dan variabel kepuasan kerja $\left(\mathrm{X}_{2}\right)$, nilainya adalah 0, maka variabel keinginan berpindah (Y) nilainya positif sebesar 4,895 . 
2. Koefisien $X_{1}=0,505$

Nilai koefisien dari variabel stres kerja adalah 0,505 dengan tingkat signifikansi 0,001 . Berarti setiap peningkatan stres kerja, akan meningkatkan keinginan berpindah sebesar 0,505 pada karyawan Sales PT Sinar Mutiara Cakrabuana. Hasil ini menunjukan bahwa stres kerja berpengaruh terhadap keinginan berpindah.

3. Koefisien $\mathrm{X}_{2}=(-0324)$

Nilai koefisien dari variabel kepuasan kerja adalah $(-0,324)$ dengan tingkat signifikansi sebesar 0,023. Berarti setiap peningkatan kepuasan kerja, akan menurunkan keinginan berpindah sebesar $(-0,324)$ pada karyawan Sales PT Sinar Mutiara Cakrabuana. Hasil ini menunjukan bahwa kepuasan kerja berpengaruh terhadap keinginan berpindah.

\section{Uji t (Uji Parsial)}

Uji t dilakukan dengan cara membandingkan nilai $t_{\text {hitung }}$ dengan nilai $t_{\text {tabel }}$ dengan nilai sig. $>0,05$. Hasil uji t dapat dilihat pada Tabel 7.

Tabel 7 Hasil Uji t

\begin{tabular}{|l|c|c|c|}
\hline Variabel & $\mathbf{t}_{\text {hitung }}$ & $\mathbf{t}_{\text {tabel }}$ & Sig. \\
\hline $\begin{array}{l}\text { Stres } \\
\text { Kerja }\end{array}$ & 3,505 & 2,00172 & 0,001 \\
\hline $\begin{array}{l}\text { Kepuasan } \\
\text { Kerja }\end{array}$ & $-2,341$ & 2,00172 & 0,023 \\
\hline
\end{tabular}

Sumber: Data primer yang diolah (2018)

Berdasarkan Tabel 7 dapat diketahui bahwa nilai dari semua variabel menunjukan $\mathrm{t}_{\text {hitung }}>\mathrm{t}_{\text {tabel, }}$ maka dapat disimpulkan bahwa pada penelitian ini semua variabel independen secara parsial berpengaruh terhadap variabel dependen.

\section{Uji F (Uji Simultan)}

Uji $\mathrm{F}$ dilakukan dengan membandingkan $\mathrm{F}$ hitung $>\mathrm{F}_{\text {tabel }}$ dengan taraf signifikansi sebesar 0,05 . Nilai $f$ tabel pada tingkat signifikansi
0,05 adalah 3,16. Hasil uji simultan dalam penelitian ini dapat dilihat pada Tabel 8.

Tabel 8 Hasil Uji F

\begin{tabular}{|ll|c|c|}
\hline \multicolumn{4}{|c|}{ ANOVA $^{\mathrm{a}}$} \\
\hline \multicolumn{1}{|l|}{ Model } & $\mathrm{F}$ & Sig. \\
\hline & $\begin{array}{l}\text { Regression } \\
\text { Residual } \\
\text { Total }\end{array}$ & 13,912 &, $000^{\mathrm{b}}$ \\
\hline
\end{tabular}

a. Dependent Variable: $Y$

b. Predictors: (Constant), X2, X1

Sumber: Data primer yang diolah (2018)

Maka dari itu dapat disimpulkan bahwa variabel independen (stres kerja dan kepuasan kerja) secara simultan berpengaruh signifikan terhadap variabel dependen (keinginan berpindah).

\section{Koefisien Determinasi}

Pada penelitian ini dalam mengevaluasi model regresi adalah menggunakan Adjusted $R$ Square. Untuk mengetahui nilai koefisien determinasi pada penelitian ini dapat dilihat pada Tabel 9:

Tabel 9 Hasil Koefisien Determinasi

\begin{tabular}{|l|c|r|r|c|}
\hline \multicolumn{1}{|c|}{ Model Summary } \\
\hline Mo & & R & Adjusted & $\begin{array}{c}\text { Std. Error } \\
\text { of the } \\
\text { del }\end{array}$ \\
\hline 1 & $\mathrm{R}$ & Square & R Square & Estimate \\
\hline 1 &, $573^{\mathrm{a}}$ &, 328 &, 304 & 1,93400 \\
\hline
\end{tabular}

a. Predictors: (Constant), X2, X1

b. Dependent Variable: $Y$

Sumber: Data primer yang diolah (2018)

Pada Tabel 9 menunjukan bahwa besarnya Adjusted $R$ Square adalah sebesar 0,304 atau sebesar 30,4\%. Hal ini menunjukkan bahwa variabel independen (stres kerja dan kepuasan kerja) mampu menjelaskan variasi yang terjadi pada keinginan berpindah sebesar $30,4 \%$ sedangkan sisanya dijelaskan oleh variabel-variabel lain yang tidak diteliti dalam penelitian ini. 


\section{KESIMPULAN DAN SARAN Kesimpulan}

Berdasarkan penelitian yang dilakukan pada karyawan Sales PT Sinar Mutiara Cakrabuana terdapat beberapa hal yang dapat disimpulkan sebagai berikut :

a. Stres kerja $\left(\mathrm{X}_{1}\right)$ berpengaruh positif signifikan terhadap keinginan berpindah (Y) pada karyawan Sales PT Sinar Mutiara Cakrabuana. Jika stres kerja naik maka keinginan berpindah ikut naik, sebaliknya jika stres kerja turun maka keinginan berpindah ikut turun.

b. Kepuasan kerja $\left(\mathrm{X}_{2}\right)$ berpengaruh negatif signifikan terhadap keinginan berpindah (Y) pada karyawan Sales PT Sinar Mutiara Cakrabuana. Jika kepuasan kerja naik maka keinginan berpindah akan turun, sebaliknya jika kepuasan kerja turun maka keinginan berpindah akan naik.

c. Stres kerja $\left(\mathrm{X}_{1}\right)$ dan kepuasan kerja $\left(\mathrm{X}_{2}\right)$ berpengaruh signifikan terhadap keinginan berpindah (Y) pada karyawan Sales PT Sinar Mutiara Cakrabuana dengan persamaan $\mathrm{Y}=4,895+0,505 \mathrm{X}_{1}$ $0,324 X_{2}$.

\section{Saran}

Berdasarkan penelitian yang dilakukan pada karyawan Sales PT Sinar Mutiara Cakrabuana terdapat beberapa hal yang dapat disarankan sebagai berikut :

a. Stres Kerja $\left(\mathrm{X}_{1}\right)$, merupakan variabel yang mempunyai pengaruh paling besar terhadap keinginan berpindah pada karyawan Sales PT Sinar Mutiara Cakrabuana. Adapun saran yang dapat diberikan terhadap stres kerja adalah memberi perhatian pada tuntutan tugas, karena responden memberikan tanggapan tinggi terkait indikator ini. Saran untuk indikator tersebut adalah sebaiknya PT Sinar Mutiara Cakrabuana dapat menyesuaikan kemampuan karyawan Sales dengan tugas yang diberikan. b. Kepuasan kerja $\left(\mathrm{X}_{2}\right)$, merupakan variabel berpengaruh kedua terhadap keinginan berpindah pada karyawan Sales PT Sinar Mutiara Cakrabuana. Adapun saran yang dapat diberikan terhadap kepuasan kerja adalah memberikan kesempatan karyawan untuk berkembang, karena responden memberikan tanggapan rendah terkait indikator ini. Saran untuk indikator tersebut adalah sebaiknya PT Sinar Mutiara Cakrabuana dapat memberikan kesempatan-kesempatan karyawan Sales untuk berprestasi dan layak mendapatkan posisi yang lebih baik dalam bekerja.

\section{DAFTAR PUSTAKA}

Bhatnagar, Jyotsna. 2014. "Mediator Analysis In The Management Of Innovation In Indian Knowledge Workers: The Role Of Perceived Supervisor Support, Psychological Contract, Reward And Recognition And Turnover Intention". The International Journal of Human Resourc Management Vol. 25, No. 10, 1395-1416.

Ferdinand, Augusty. 2006. Metode Penelitian Manajemen. Semarang:Badan Penerbit Universitas Diponegoro.

Ghozali, Imam. 2016. Aplikasi Analisis Multivariete Dengan Program IBM SPSS 23. Semarang:Badan Penerbit Universitas Diponegoro.

Munandar, Ashar Sunyoto. 2014. Psikologi

Industri dan Organisasi. Jakarta:UI-

PRESS.

Octaviani, Heny. 2015. "Person-Organization

Fit, Kepuasan Kerja, Dan Turnover

Intention: Studi Empiris Pada Karyawan

Generasi Y Industri Perbankan Di

Indonesia." Jurnal Manajemen (Vol. 12

No. 2 November 2015: 111-128).

Pawesti, Ristia dan Rinandita Wikansari. 2016. "Pengaruh Kepuasan Kerja Terhadap Intensi Turnover Karyawan Di Indonesia." Jurnal Ecopsy, Volume 3, Nomor 2, Agustus 2016:49-67. 
Priyono dan Marnis. 2008. Manajemen

Sumber Daya Manusia.

Sidoarjo:Zifatama Publisher.

Priyono. 2010. Manajemen Sumber Daya

Manusia. Sidoarjo:Zifatama Publisher.

Ramamurthi, Kavitha, Amin Vakilbashi, Siti Zaleha Abdul Rashid, Mozhdeh Mokhber, Rohaida Basiruddin. 2016. "Impact of Job Stressors Factors on Employees Intention to Leave Mediated by Job Engagement and Dispositional Factors." International Review of Management and Marketing Vol. 6 Issue 3.

Robbins, Stephen P. dan Timothy A. Judge. 2018. Essentials of Organizational Behavior. England:Pearson Education.

Sugiyono. 2014. Metode Penelitian Bisnis. Bandung:Penerbit Alfabeta.
Sunaryo, Silvia Puspaningrum dan Pantius D. Soeling. 2014. "Pengaruh Stres Kerja Terhadap Turnover Intention Frontliner Darat Pada Pt Garuda Indonesia (Persero) Tbk Area Jakarta Raya (Studi Perbandingan Pada Pegawai Tetap Dengan Pegawai Outsource)".

Wong, Yui-tim, Yui-Woon Wong, Chi-sum Wong. 2014. "An Integrative Model Of Turnover Intention Antecedents And Their Effects On Employee Performance In Chinese Joint Ventures." Journal of Chinese Human Resource Management Vol. 6 No. 1, 2015 pp. 71-90.

Zainal, Veithzal Rivai. et al. 2014. Manajemen Sumber Daya Manusia Untuk Perusahaan. Jakarta:Rajagraf. 
Kurniawati, dkk/AdBis 20 (1): 37 - 46 